\title{
Ética, Retórica e Poética no Diálogo dos Oradores e a concepção de História em Tácito
}

Fábio Duarte Joly*

Resumo: Este artigo busca analisar o Diálogo dos Oradores, de Tácito, relacionando sua estrutura compositiva e temas a uma discussão acerca da concepção de História que norteia a obra taciteana em geral. Aponta-se a inserção de Tácito na tradição filosófica da Nova Academia, com sua ênfase na equidade, e a aproximação entre a história e a tragédia no tocante a suas finalidades éticas.

Palavras-chave: Diálogo dos Oradores. Tácito. Retórica. História.

\section{Introdução}

O Diálogo dos Oradores, de Tácito, cujo tema - o declínio da eloquência - é tratado mediante aproximações entre a poesia e a ora-tória, possibilita uma avaliação da concepção de História de Tácito, em paralelo com suas outras obras, como as Histórias e os Anais. Tal perspectiva é pouco aplicada à análise do Dialogus, embora permita discutir as relações entre retórica e história, tão candentes na produ-ção acadêmica sobre historiografia antiga. ${ }^{1}$

\footnotetext{
* Professor adjunto de História Antiga e Medieval na Universidade Federal do Recôncavo da Bahia. Membro do Laboratório de Estudos sobre o Império Romano (LEIR). E-mail: joly@uol.com.br
}

Anos 90, Porto Alegre, v. 16, n. 30, p. 19-43, dez. 2009 
Durante longo tempo sustentou-se que o Dialogus seria a primeira obra de Tácito, escrita em 97 e antes da publicação da Vida de Agrícola e da Germânia. Contudo, a dedicação da obra a um certo Fábio Justo (Dialogus, I, 1), ${ }^{2}$ cônsul em 102 e governador da Síria em 106, levou estudiosos a localizar a obra entre este período, privilegiando-se a primeira data. ${ }^{3}$ Pierre Grimal, em seu estudo sobre Tácito, reforçou esta hipótese ao considerar o Dialogus como um elogio da monarquia de Trajano, colocando então sua publicação nos primeiros anos deste reinado (GRIMAL, 1990, p. 153).

A data dramática situa-se entre 74 ou 75 , ou seja, sob o reinado de Vespasiano. Tácito, a pedido de Fábio Justo, propõe-se a relatar um diálogo, que ouvira quando jovem, acerca do declínio da eloquência. Quatro são os interlocutores: Curiatius Maternus, Marcos Aper, Julius Secundus e Vipstanus Messalla. Sobre o primeiro pouco se sabe. É certo que era um senador, mas sua origem é duvidosa (SYME, 1967, Apêndice 90). Marcus Aper e Julius Secundus, também senadores, são de origem gaulesa (SYME, 1967, Apêndice 91; BRINK, 1993, p. 338). Messalla, outro senador, é o único romano no debate e provém de uma família aristocrata. Em breves linhas, assim podemos dividir a obra. A recepção negativa que teve na corte a tragédia Catão de Maternus é o acontecimento que levou a um debate sobre o declínio da eloquência (Dialogus, II, 1IV, 2). Segue-se então um discurso de Aper (Dialogus, V, 1-X, 8) sobre a utilidade da oratória, visando a exortar Maternus a retornar à sua prática em vez de compor tragédias. Maternus rebate a fala de Aper com um discurso em favor da poesia para justificar sua posição (Dialogus, XI, 1-XIII, 6). Com a chegada de Messalla, Secundus propõe a este que ele profira uma defesa dos oradores antigos (Dialogus, XVI, 1). É o que ele faz (Dialogus, XXV, 1-XXXV, 5), após um segundo discurso de Aper (Dialogus, XVI, 4-XXIII, 6), elogiando a oratória moderna. Um terceiro par de discursos encerra a obra. Secundus procura explicar o declínio da oratória tendo em vista as condições políticas do Princi-pado (Dialogus, XXXVI, 1$\mathrm{XL}, 1)$. O discurso final de Maternus segue esta mesma linha de raciocínio (Dialogus, XL, 2-XLII, 2). 
O tema da obra é um topos, presente em outros escritores do período imperial: Veleio Patérculo (1,16-18), Sêneca, o Velho (Controuersia 1, praef. 6-10), Petrônio (88, 1-2), Sêneca (Epistulae 114, 1-2), Plínio, o Velho (Naturalis Historia, 14, 1, 3-7), Quintiliano (Institutio Oratoria, 8, 6, 76) e Plínio, o Jovem (Epistulae, 2, 14). ${ }^{4}$ Além disso, a obra enquadra-se no gênero do diálogo, sendo Cícero seu modelo, a ponto mesmo de haver um paralelo entre o De oratore e o Dialogus quanto à linguagem usada e à disposição dos personagens (LUCE, 1993, p. 12). É no discurso de Messalla que encontramos, em maior número, referências a Cícero. ${ }^{5}$ Esta ênfase nas semelhanças entre Tácito e Cícero, no tocante à forma do Dialogus, acabou por desviar a atenção das especificidades desta obra, levando os pesquisadores a estudá-la em separado dos seus demais escritos. Isto, em última instância, se deve ao fato de se considerá-la exclusivamente como um exemplar de "crítica literária" que a Antiguidade legou (GRUBE, 1965). Contudo, o Dialogus está intimamente relacionado ao restante da obra taciteana, não sendo apenas uma reflexão sobre literatura, como alerta Von Albrecht (1995, p. 1121). Embora não se detenha em aprofundar esta relação, o autor ressalta como características da obra histórica de Tácito: a parcial admissão da superioridade do presente, a aceitação do fato da monarquia, e os rudimentos de uma evolução para uma nova ética política de adequação (VON ALBRECHT, 1995, p. 1098).

A nosso ver, os três pontos acima se encontram no Dialogus, sendo um dos objetivos deste o de precisamente descartar o topos de que o passado é superior ao presente, contido no topos do declínio da eloquência. Relacionada a este ponto, por sua vez, está a proposta de uma ética política, adequada ao Principado, apresentada mediante a discussão da forma de discurso cabível ao regime imperial.

\section{Retórica, Poética e Ética no Diálogo dos Oradores}

Na introdução do Dialogus, Tácito coloca a quaestio que tratará na obra: o declínio da eloquência, apresentada como sendo uma frequente indagação por parte de seu amigo Fábio Justo (Dialogus, I, 1). 
Ética, retórica e poética no Diálogo dos Oradores e a concepção...

A evidência alegada para provar tal declínio é o desuso do termo orator e sua substituição por outros como causidicus, aduocatus e patronus (Dialogus, I, 2). A esta hipótese, Tácito ajunta outra: a de saber se o declínio da eloquência é resultado de determinadas condutas humanas (Dialogus, I, 2). Tácito, portanto, indica que, na quaestio que lhe foi colocada, está subjacente um julgamento ético sobre a ação humana no presente. Em seguida, propõe-se a responder à questão relatando um diálogo que ouvira quando jovem. Seguindo a ordem da disputatio (seruato ordine disputationis, Dialogus, I, 3), apresenta as causas prováveis levantadas pelos interlocutores para o declínio da eloquência e também enfatiza que um deles mantinha a opinião oposta, que a eloquência contemporânea é superior à antiga (Dialogus, I, 3-4).

Deste modo, esta obra de Tácito pode ser entendida como uma disputatio in utramque partem, ou seja, a argumentação de uma causa, sucessivamente, de um e de outro lado da questão. Este era um exercício comum nas escolas de retórica neoacadêmicas para se tentar chegar a um grau de probabilidade suficiente para permitir a escolha e a ação (CHIAPPET'TA, 1997, p. 62). De fato, no Dialogus o tratamento do tema é feito pela contraposição de pares de discursos, cada par sendo constituído de um discurso que reconhece o declínio da eloquência e de um outro que ataca esta posição. O próprio Tácito, na introdução, faz questão de marcar estes dois extremos nos quais se pautará a disputatio. Ele inicia colocando a questão de Fábio Justo e termina com a posição oposta, que ao longo da obra é desenvolvida no discurso de Marcus Aper. A conclusão do Dialogus aponta justamente a preocupação do escritor em estabelecer um meio-termo tendo em vista a dicotomia presente/passado. A superioridade do passado frente ao presente, expressa no topos do declínio da oratória, representa antes de tudo uma oposição entre sistemas políticos, a República e o Principado.

O problema que Tácito se coloca é o de procurar qual o tipo de discurso adequado à realidade do regime imperial, necessário para a manutenção da ordem, ou seja, um discurso relacionado à premissa de que o presente tem vantagens sobre o passado. E, a partir disto, propor uma prática política correspondente que seja tanto útil como honesta, seguindo a tradição da filosofia neoacadêmica. No Dialogus isto é discutido através de uma contínua aproximação entre Retórica e Poética no que diz respeito à composição do discurso ideal para este fim. $\mathrm{O}$ 
primeiro par de discursos, composto por um de Aper e outro de Maternus, centra-se na respectiva utilitas da oratória e da poesia. O segundo par centra-se nas diferenças entre o orador imperial, cuja defesa cabe a Aper, e o orador republicano, defendido por Messalla. O principal tema dessas falas é o da forma dos discursos e sua adequação ao público ouvinte, contudo, sempre se estabelecendo um paralelo entre o falar e o agir do orador. Os dois últimos discursos do Dialogus, o de Secundus e um outro de Maternus, centram-se na relação entre política e oratória, mais precisamente no impacto do Principado no exercício da eloquência. É pelo discurso final de Maternus que Tácito reverte o topos com o qual iniciara a obra e propõe uma aproximação entre o orador republicano e o poeta imperial quanto à função que o discurso de ambos deve cumprir, a de indicar condutas caracterizadas pela justa medida.

Esta conclusão a que permite chegar a análise do Dialogus remete, por sua vez, à concepção de História de Tácito. Nas suas obras históricas, principalmente as Histórias e os Anais, também se nota a preocupação do escritor em afirmar a superioridade do presente frente ao passado e em propor exemplos de condutas pautadas, não por extremos, mas por um justo meio, visando uma adequação ao regime imperial.

\section{O orador e o poeta imperiais}

Os primeiros discursos de Aper e Maternus apresentam a questão da aproximação entre a figura do orador e a do poeta. Com esta primeira fala de Aper, Tácito introduz um tema que será desenvolvido, com maior detalhe, no segundo discurso de Aper: o poeta como um referencial para a composição de discursos. Com o discurso de Maternus, Tácito trata do tema da função ética do poeta, o qual também retomará no último discurso deste personagem. Em paralelo com os pontos acima, temos a relação entre gênero de discurso e Ética, visto que a defesa da oratória por Aper e a da poesia por Maternus estão associadas à justificativa da adoção de uma determinada conduta no Principado.

A leitura do discurso de Aper em defesa da oratória revela uma proposta de aproximar o fazer do poeta daquele do orador. Esta apro- 
Ética, retórica e poética no Diálogo dos Oradores e a concepção...

ximação já se anuncia na crítica que faz a Maternus antes do seu discurso. Aper lamenta que Maternus dedique mais tempo à composição de tragédias do que ao cultivo dos discursos para causas (Dialogus, III, 4). Deste modo, apenas aparentemente o poeta e o orador divergem, pois Aper não descarta a possibilidade de que poeta seja orador, visto que conclama Maternus a fazê-lo. No início de seu discurso, distingue os poetas incapazes de atuar em causas (Dialogus, V, 3) daqueles que capazes, como Maternus, o qual teria nascido para a eloquência (natus ad eloquentiam uirilem et oratoriam, Dialogus, V, 3), mas renunciava a este saber (Dialogus, V, 3). Assim, para Aper, o que destaca Maternus é o fato de ele possuir um studium tanto da poesia como da oratória. Tendo indicado isto, Aper passa a contrastar a utilidade da oratória e a da poesia, pois apenas quanto à função elas divergiriam.

A oratória é útil por ser como uma arma, permitindo o ataque e a defesa seja no tribunal, no senado ou diante do imperador (Dialogus, $\mathrm{V}, 5)$. O orador é comparado ao gladiador. No lugar da couraça e do gládio (lorica et gladius), serve-se da palavra. Esta comparação também se encontra nas Controuersiae de Sêneca, o Velho. Discutindo a ocorrência deste paralelo nos escritos deste, P. Sinclair observa que isto é significativo de como um provincial (Sêneca provinha da Hispânia) entendia o exercício da oratória em Roma, necessário ingressar na concorrida política romana (SINCLAIR, 1995, p. 123). Aper também é um provincial, originário da Gália, e daí sua ênfase na eloquência como um elemento para integração na ordem política romana e ascensão dentro ela. Isso se depreende do modo como descreve sua carreira. Segundo ele, apesar de ser um "homem novo" e nascido em cidade pouco reconhecida (quo bomo nouns et in cinitate minime fauorabili, Dialogus, VII, 1), ascendeu o quanto lhe permitiu sua "capacidade para falar" (dicendo facultatis, Dialogus, VII, 1).

As referências aos oradores Eprius Marcellus e Vibius Crispus apresentam o mesmo conteúdo. Apesar de não originários de famílias ilustres (sordidius et abiectius nati sunt, VIII, 3) e pobres (notabilior paupertas, VIII, 3), conseguiram promover-se graças à oratória, sendo exemplos da utilidade desta arte (eo clariora et ad demonstrandam oratoriae eloquentiae utilitatem inlustriora exempla sunt, Dialogus, VIII, 3). A principal utilidade da oratória, para Aper, é a geração de clientela (Dialogus, VI, 1-3). Neste contexto, a produção poética não teria ser- 
ventia, pois não produz este benefício (nec aut amicitiam inde refert aut clientelam, IX, 4), uma vez que o poeta geralmente tem que se retirar da vida pública para compor (Dialogus, IX, 6).

No final do discurso, após novamente exortar Maternus a voltar-se à oratória, Aper conclui com o argumento de que a oratória é mais segura que a poesia, pois permite evitar ofensas a personagens poderosos. Ele está referindo-se aqui à recepção que teve a tragédia Catão, de Maternus, na corte de Vespasiano. Na prática da oratória, o orador pode desculpar-se caso ofenda alguém importante, alegando que está exercendo o ofício de advogado (Dialogus, X, 6). A tragédia, ao contrário, pode ser considerada uma crítica indireta, pois se parte do princípio de que o poeta escolheu seu personagem de forma premeditada (meditatus videris elegisse personam notabilem, Dialogus, X, 6). Ou seja, entende-se que o poeta exterioriza suas opiniões através dos seus personagens. Portanto, já nessas observações percebe-se a função do poeta de criticar determinadas condutas, função esta que ficará mais evidente no discurso com o qual Maternus responde a Aper.

Neste discurso, Maternus começa ressaltando a função de suas tragédias na vida pública romana, as quais lhe trouxeram renome. Declara que a recitação de sua tragédia Nero despedaçou o poder de Vatinius (Dialogus, XI, 2), indivíduo que era próximo a Nero e que gozava de grande influência. Novamente o poeta é aproximado do orador. $\mathrm{O}$ atuar em uma causa não difere substancialmente do recitar tragédias: ambas, no caso, tem como finalidade acusar um indivíduo. Em outro momento também compara oradores e poetas roma-nos que compuseram tragédias (Dialogus, XII, 6). A diferença que Ma-ternus estabelece entre a poesia e a oratória reside na existência tran-quila que a primeira proporciona. Todavia, não se trata de um afastamento total da vida pública, mas sim de uma outra alternativa de influenciar esta. Ilustra isso tomando como exemplo Virgílio, o qual, mesmo vivendo em isolamento, tinha prestígio com o imperador e notoriedade junto ao povo (Dialogus, XIII, 1). Em outra passagem ele assim explica a função do poeta:

Feliz aquele outro, e para falar do nosso modo, século áureo, ausente de oradores e crimes, abundava em poetas e oráculos, que cantavam os bons atos e não defendiam os maus perpe-trados. (Dialogus, XII, 3) 
A expressão aureum saeculum é uma alusão a Virgílio, à idade de ouro sob o reinado de Saturno, como aparece nas Geórgicas (II, 532540). ${ }^{6}$ Maternus transpõe para um passado mítico a tarefa ideal do poeta, a de cantar os bons feitos e não defender os maus. Este objetivo, como observou Heilmann (1989, p. 389), não difere muito daquele do historiador.

\section{O orador imperial e o orador republicano}

No segundo discurso de Aper, em defesa dos oradores modernos, Tácito desenvolve a relação entre poesia e oratória no tocante à composição dos discursos adequados ao público do Principado. $\mathrm{O}$ discurso de Messalla, em prol dos oradores antigos, é utilizado por Tácito como um exemplo de discurso inadequado para esta época. Contudo, Tácito ressalta uma das características da oratória republicana, a sua finalidade ética, o que acaba por aproximá-la da poesia e da história. Também neste par de discursos permanece a relação entre Retórica e Ética, pois as formas de discurso, defendidas pelos protagonistas, estão relacionadas às formas de vida do orador.

O segundo discurso de Aper ainda centra-se na aproximação entre o poeta e o orador, porém a linha de argumentação difere da que seguiu no anterior. Da utilitas da oratória passa a tratar do genus dicendi adequado ao público de seu tempo. Como vimos, esta questão da audiência fora brevemente mencionada em seu primeiro discurso, quando comparou a recepção do discurso judiciário com aquela que a tragédia obtém. Neste último discurso, Aper, através da crítica aos oradores antigos, especifica a forma que o discurso deve ter a fim de agradar à audiência. O recurso à poesia será entendido neste contexto.

A primeira parte do discurso de Aper consiste em negar o topos de que o presente é inferior ao passado. Começa pondo em dúvida a própria qualificação de "antigos". Ulisses e Nestor seriam antigos, pois viveram há mais de mil e trezentos anos, e não Demóstenes ou Hipérides, os quais distam trezentos anos da época em que se passa o diálogo (Dialogus, XVI, 5-6). Apoiando-se em um conceito de ano proposto por Cícero, ${ }^{7}$ alega que Demóstenes pode ser visto como um orador contemporâneo (Dialogus, XVI, 7). Este argumento de 
Aper revela uma tentativa de abolir a dicotomia entre presente e passado como fora expressa na alusão à idade de ouro virgiliana por Maternus. A referência a Ulisses e Nestor é, neste contexto, significativa, uma vez que no discurso de Maternus há um paralelo entre Homero e Virgílio (Dialogus, XII, 5-6). Ao tratar dos oradores latinos (Dialogus, XVII), Aper também rejeita a qualificação de "antigos" atribuída a eles, utilizando o mesmo argumento do pequeno lapso temporal que os separa do momento presente, como no caso de Cícero (Dialogus, XVII, 3).

Após esta crítica inicial do topos, a segunda parte do discurso de Aper desenvolve o argumento de que os gêneros e as formas do discurso variam de acordo com as épocas (Dialogus, XVIII, 2), visto que o orador deve adaptar-se às exigências do público de seu tempo. Contrastando a audiência do período republicano com a do império, afirma que a um público imperito e rude correspondia um discurso de longa duração e dividido segundo os tratados de Retórica de Hermágoras e Apolodoro (Dialogus, XIX, 2-3). Devido a estas características da audiência, o recurso a preceitos de filósofos também era válido. Porém, no Principado, o público já é conhecedor deste recurso e não mais lhe agrada um discurso longo. Mesmo para ter sucesso em suas causas o advogado deve limitar seu discurso ao tempo estabelecido pelos juízes. Em suma, a questão que Tácito aponta, pelo discurso de Aper, é a do caráter rotineiro de uma certa forma de discurso, o que resulta na perda da eficácia frente ao público. ${ }^{8}$ A solução proposta é a adoção de um decoro poético:

De fato é ainda exigido do orador um decoro poético [poeticus decor], não manchado pela velharia de Ácio ou Pacúvio, mas engrandecido a partir do santuário de Horácio, Virgílio e Lucano. (Dialogus, XX, 5).

Para Aper, apenas um discurso ornado pela poesia é capaz de prender a atenção do público. Temos, então, novamente a imagem do poeta como um referencial para o orador. No discurso de Maternus isso foi expresso de forma clara, o poeta como o que canta os bons feitos e, neste segundo discurso de Aper, o poeta é um guia para a composição de discursos, em substituição aos tratados de Retórica. 
A seleção de poetas que Tácito aqui apresenta não é casual. Mencionamos que o discurso de Maternus, elogiado por Secundus que o classificou de "mais próximo, pelo discurso, dos poetas do que dos oradores" (Dialogus, XIV, 2), destaca-se por suas alusões a Virgílio (Dialogus, XII, 6; XIII, 1-2; 5) e, no seu último discurso, Horácio é implicitamente mencionado.

Também neste discurso de Aper continua presente a relação entre Retórica e Ética. No primeiro discurso o elogio da oratória era paralelo à defesa de uma determinada conduta, caracterizada pela importância das relações de patronato e riqueza. No segundo discurso isso transparece na comparação entre o discurso ornado e a domus de um pater familias rico, a qual também deve ser ornamentada (Dialogus, XXII,). Novamente, a um tipo de discurso corresponde um modus viuendi.

O discurso de Messalla, em resposta ao de Aper, é baseado no topos de que o passado é superior ao presente. Sua fala enfatiza a relação entre Retórica e filosofia, tomando Cícero como parâmetro, e nega qualquer aproximação com a poesia. No plano formal, caracteriza-se por constantes digressões, o que leva a duas intervenções da parte de Maternus. Uma hipótese a ser colocada sobre o papel deste discurso no conjunto da obra é a de que Tácito pretendia exemplificar a ineficácia daquele discurso que fora alvo de críticas no segundo discurso de Aper, ou seja, um discurso estruturado por longas divisões e que insiste no que é já conhecido pela audiência (Dialogus, XIX, 3-4).

O primeiro argumento de Messalla contra o de Aper - as formas e tipos de discurso mudam com as épocas - consiste em apontar que há traços comuns entre os oradores antigos. Para Messalla, a variação quanto ao gênero dos discursos é secundária, visto que, quanto ao iudicium e à uoluntas, os oradores antigos assemelhavam-se (Dialogus, XXV, 4-5). Posicionando-se neste sentido, Messalla desloca o debate da questão da audiência, privilegiada por Aper, para o problema do caráter do orador.

Logo, a crítica da oratória moderna por Messalla é principalmente uma crítica ao comportamento dos oradores modernos. Isso fica claro quando compara estes oradores a histriões "que pela petulância das palavras, pela inconstância das frases e licença da com- 
posição se exprimem à maneira dos histriões" (Dialogus, XXVI, 2). Nesta desqualificação, Messalla serve-se de palavras (lasciuia, leuitas e licentia) presentes tanto no domínio da Retórica como da Ética. O mesmo ocorre quando indica que a urbanidade (Dialogus, XXVI, 6) deve ser uma característica do orador e de seu discurso. $\mathrm{O}$ adjetivo urbanus relaciona-se a "romano", dado significativo considerando-se que Aper é um provincial enquanto Messalla é o único romano no debate. É perceptível, por meio da intervenção de Maternus, nesta altura do discurso, que Messala conduz sua fala para uma crítica ética dos oradores modernos. E Maternus pede a este que não se afaste do exame das causas do declínio da eloquência, em virtude de Aper ter censurado seus antepassados (Dialogus, XXVII).

$\mathrm{Na}$ segunda parte do discurso, Messalla propõe-se a explicar tais causas, mas ainda sob o prisma ético. O declínio da eloquência é entendido como resultado de uma degradação dos costumes:

Quem de fato ignora que tanto a eloquência como as outras artes terem se afastado daquela antiga glória não pela ausência de homens, mas pela inação da juventude e negligência dos pais, pela falta de conhecimento dos que ensinam e esquecimento dos costumes antigos? (Dialogus, XXVIII, 2)

As evidências acima apontadas se encontram em outros escritores, como Sêneca, o Velho, e Petrônio. O próprio Maternus observa, em seu discurso, que a eloquência moderna tem um uso recente, nascido dos maus costumes (Dialogus, XII, 2). Ou seja, Messalla irá falar sobre o que é notório para todos, fato que Tácito enfatiza com a frase "E quem ignora isso?". Messalla passa, então, a justificar o declínio da eloquência comparando o presente com o passado: no caso, a educação infantil entre os antigos e os modernos, e a educação do orador antigo e a do moderno.

No passado era a mãe quem cuidava dos filhos e não uma escrava (non in cellula emptae nutricis, sed gremio ac sinus matris educabantur, Dialogus, XXVIII, 4). Além disso, cabia à mãe dirigir os estudos do filho, incentivando-o a dedicar-se à vida militar, ao direito ou à eloquência (Dialogus, XXVIII, 6-7). No presente, pelo contrário, as crianças eram entregues a qualquer escrava (alicui ancillae). Os próprios 
pais acostumavam os filhos aos vícios e o fato de viverem em Roma levava as crianças a gostar de histriões, combates de gladiadores e corridas de cavalos (Dialogus, XXIX, 2-3), relegando o estudo das boas artes. Esta referência aos histriões e gladiadores também pode ser entendida como uma crítica à oratória defendida por Aper. Messalla anteriormente acusara os oradores modernos de imitarem histriões (XXVI, 2) e a menção aos gladiadores remete à comparação feita por Aper entre oratória e combate. Desta crítica aos costumes Messalla passa a criticar a oratória moderna, comparando-a com a antiga.

Após louvar a disciplina dos oradores antigos frente aos estudos (Dialogus, XXX, 2), Messalla passa a enumerar, tomando Cícero como exemplo, os conhecimentos que estes possuíam: direito, filosofia (XXX, 3), geometria, música e gramática (XXX, 4; XXXI, 7), conferindo particular importância ao conhecimento da filosofia. Deixa claro que a eficácia do discurso depende do quanto o orador conhece de filosofia (Dialogus, XXXI, 3-4) e do modo como recorre às doutrinas dos vários filósofos (XXXI, 5-7). Desta maneira, novamente Tácito constrói o discurso de Messalla como uma antítese ao primeiro discurso de Aper, o qual negligenciava o recurso à filosofia.

A comparação entre passado e presente continua, quando após uma segunda intervenção de Maternus (Dialogus, XXXIII, 1), Messalla se refere à educação oratória dos antigos e modernos. No passado (apud maiores nostros) os jovens iniciavam-se na eloquência conduzidos pelos pais, que os confiavam a um orador que ocupava importante posição na cidade (Dialogus, XXXIV, 1). Aprendia-se a eloquência na prática cotidiana, através do acompanhamento deste orador (Dialogus, XXXIV, 4). Por outro lado, no presente, os jovens praticam suasoriae e controuersiae em escolas de oradores (Dialogus, $\mathrm{XXXV}, 4)$, onde predomina a falta de reuerentia, pois as crianças ficavam entre crianças e os adolescentes entre adolescentes (Dialogus, $\mathrm{XXXV}, 3)$. Ou seja, predominavam relações entre iguais e não entre um inferior e outro superior, como no passado. No passado, a disciplina no aprendizado retórico e na elaboração dos discursos, adequando-se às regras, correspondia às relações verticais de poder. No presente a licentia que caracterizava o ensino da retórica e a própria composição dos discursos (recurso à poesia) era acompanhada por uma quebra da reuerentia nas relações sociais. 
Deste modo, a relação entre Retórica e Ética, apontada de forma superficial na crítica à forma de discurso defendida por Aper (Dialogus, XXVI, 2), é desenvolvida a partir do tema da educação do orador. Da diferença entre a educação antiga e a moderna, Messalla retira uma conclusão: a educação antiga permitia que se alcançasse uma uera eloquentia (Dialogus, XXXIV, 4), enquanto a moderna não, pois se pratica a partir de assuntos que se afastavam da verdade (abhorrenti a ueritate, Dialogus, XXXV, 4). Quando Messalla trata da função do orador assim define sua matéria:

(...) examinar o que é bom e mal, honesto e torpe, justo e injusto; esta é a matéria que cabe ao orador dissertar. Pois nos discursos judiciários normalmente sobre a equidade, nos deliberativos sobre a utilidade, nos elogios sobre a honestidade dissertamos. (Dialogus, XXXI, 1-2).

Aproximar-se da verdade é dever do orador, através do tratamento do que é útil, honesto e da equidade entre estes conceitos, como fica evidente no paralelo acima estabelecido entre os genera dicendi e os conceitos éticos. Este paralelo, aliás, é o mesmo que se observa tomando-se em conjunto o De officiis e as Partitiones Oratoriae, de Cícero. Como demonstrou Angélica Chiappetta:

(...) os deveres relativos ao honesto aparecem no livro I, do De officiis, divididos em quatro partes: o conhecimento do verdadeiro, a manutenção da sociedade entre os homens, a formação de um ânimo robusto e a conveniência no agir e no dizer. Destas quatro partes, sai o material para o elogio e o vitupério. Ao tomar uma decisão, objetivo do discurso deliberativo, o fim observado deve ser a utilidade, discutida no livro II do De officiis. Já no discurso judiciário, o fim a ser observado é a equidade, presente no livro III, do De officiis. (CHIAPPETTA, 1997, p. 138).

Tácito assim aproxima o orador republicano e o poeta imperial, pois a função de ambos consiste em tratar do que é bom e mal. Todavia, o escritor, por meio do discurso de Messalla, procura mos- 
Ética, retórica e poética no Diálogo dos Oradores e a concepção...

trar que esta função do orador no Principado necessita de um discurso não mais pautado em argumentos de conhecimento geral e apoiado no topos da superioridade do passado em relação ao presente. Centrar um discurso em tais ideias, além de ter pouca eficácia frente à audiência, reduz sua função ética, pois não indica condutas adequadas para o presente. No discurso final de Maternus, que veremos a seguir, Tácito indica uma solução para este impasse, visando aproximar a figura do poeta e do orador tendo em vista o topos inverso: a superioridade do presente frente ao passado.

\section{O poeta imperial e o orador republicano}

Após o discurso de Messalla, ocorre um de Secundus e outro de Maternus. Devido a uma quebra no manuscrito não possuímos o começo e o fim do discurso de Secundus (assim como se perdeu o fim do de Messalla) e o começo do de Maternus. Porém, é possível ver uma unidade, quanto ao conteúdo, nestes dois discursos. Ambos tratam de combater a idealização do passado republicano, tal como aparece na fala de Messalla.

O discurso de Secundus explica o declínio da eloquência como resultado do estabelecimento do Principado. Segundo ele, a República caracteriza-se por ter sido um período de perturbatio e licentia, o que contribuía com material para o orador (XXXVI, 3). Na ausência de um "indivíduo moderador", era o orador quem persuadia o povo errante (erranti populo persuaderi poterat, Dialogus, XXXVI, 2), dirigindo-se a ele e também ao Senado (Dialogus, XXXVI, 5). Disto decorria o acúmulo de honras e aumento de influência (Dialogus, XXXVI, 4). Secundus reconhece que o regime instaurado por Augusto, ao esta-belecer a paz, acarretou o declínio da eloquência, mas afirma que foi melhor assim, pois restabeleceu a ordem (Dialogus, XXXVII, 2-5). Este discurso, ao caracterizar negativamente a República, já revela uma valorização do presente. O discurso de Maternus, que encerra o Dialogus, centra-se neste aspecto. Diz ele que a eloquência republicana é discípula da licença (sed est magna illa et notabilis eloquentia alumna licentia, Dialogus, XL, 2) e que o monopólio do exer- 
cício da jus-tiça pelo imperador tornou-a desnecessária, mas, em contrapartida, assegurou a concórdia no Estado. Daí o conselho de Maternus aos presentes:

Acreditem, grandes homens e hábeis no falar, se vós nos séculos anteriores ou aqueles homens, aos quais nos voltamos, neste século tivessem nascido, e um deus mudasse os períodos de vossa vida, nem a vós teriam faltado aquele sumo louvor e glória na eloquência nem àqueles medida e temperamento; contudo, já que ninguém pode, ao mesmo tempo, obter grande renome e tranquilidade, o seu bom século quem quer que seja pode aproveitar, sem denegrimento dos outros (Dialogus, XLI, 5)

Parafraseando Horácio (Saturae, II, 7, 22-27, apud BRINK, 1993, p. 335), Maternus aconselha a adoção de uma conduta pautada por um meio-termo. Tácito, no Dialogus, atribui ao poeta imperial a função de indicar a conduta adequada no Principado, resgatando uma tarefa do orador republicano (BARTSCH, 1994, p. 118). O fato de ser Maternus o personagem com quem Tácito conclui a obra também indica sua preferência por um discurso próximo ao poético para cumprir uma função ética, ${ }^{10} \mathrm{e}$ também por uma conduta nem tanto direcionada pelos parâmetros do passado e pela crítica do presente, como exemplificou com Messalla, e nem voltada exclusivamente para a busca de prestígio social no presente, através do uso da eloquência, como no caso de Aper. O Maternus retratado por Tácito equilibra a tensão entre passado e presente, ao representar uma conduta intermediária. O renome do poeta advém do papel que ocupa na vida pública, indicando aos demais indivíduos, por meio de seus escritos, como devem procurar agir dada a realidade do Principado. Esta conclusão do Dialogus, sintetizando a relação entre poesia, oratória e Ética que atravessa toda esta obra, abre um caminho para a abordagem da concepção de História em Tácito. Também o historiador deve instruir seus leitores sobre a conduta adequada, ou seja, que se atenha a um meio-termo para o Principado, uma realidade que deve ser aceita, e não criticada através de uma idealização da República. 
Ética, retórica e poética no Diálogo dos Oradores e a concepção...

\section{A História em Tácito}

Em um trecho dos Anais, no qual Tácito comenta sobre a escrita da História, percebe-se a mesma problemática presente no Dialogus, a saber, a comparação entre passado e presente:

Não desconheço que muitas das coisas que referi e referirei talvez pareçam pequenas e fugazes para se lembrar; mas ninguém medirá nossos anais com o que foi escrito por aqueles que compuseram os antigos feitos do povo romano. Para aqueles grandes guerras, reis abatidos e capturados, ou, se por ventura, às coisas internas se voltavam, discórdias entre cônsules e tribunos, leis agrárias e frumentárias, disputas entre a plebe e os optimates, lembravam em livre curso. Para nós o trabalho é restrito e sem glória. De fato uma paz imóvel e moderadamente estimulada, fatos tristes na cidade e um imperador que era indiferente quanto a alargar o império. Contudo não terá sido sem uso perscrutar aquelas coisas aparentemente fugazes a partir das quais muitas vezes o motivo de grandes coisas tem origem.

Todas as nações e cidades são regidas ou pelo povo ou pelos principais cidadãos ou por um só. Uma forma de governo escolhida e composta a partir destas é mais fácil de ser louvada do que produzida, ou, caso venha a ser, não pode ser duradoura. Pois então que a plebe era forte, que os senadores tinham poder, deviam ser conhecidas a natureza do vulgo e por quais modos, com moderação, fosse tratado; os que sabiam com perfeição o caráter dos senadores e optimates, eram considerados experientes e conhecedores dos tempos. Como na situação inversa Roma não é outra coisa que se um imperasse, esta busca e transmissão terá sido de interesse, pois poucos por prudência as coisas honestas das más, as úteis das prejudiciais discernem, a maioria é ensinada pelo que acontece aos outros. Logo, estas coisas devem ser de proveito, ainda que tragam o mínimo de deleite: pois a situação de povos, variedades de combates, ilustres mortes de chefes retém e restauram a disposição dos que lêem. Nós, ordens cruéis, acusações consecutivas, amizades falazes, a ruína de inocentes e

Anos 90, Porto Alegre, v. 16, n. 30, p. 19-43, dez. 2009 
mesmas causas de seus fins, fatos óbvios quanto à semelhança e à quantidade. Então para os antigos escritores um raro detrator havia, e nem interessava qual dos exércitos, púnicos ou romanos, com mais abundância tenhas elevado. Mas de muitos que de Tibério, enquanto reinava, sofreram punição ou infâmias, permanecem descendentes. Mesmo que as próprias famílias já estejam extintas, encontrarás os que pela semelhança dos costumes julgam os maus feitos alheios imputados a si. Até para a glória e o que é virtuoso há inimigos, como que, a partir do que é muito semelhante, acusando ações contrárias. Mas volto ao que comecei. (Annales, IV, 32-33).

Tácito inicia traçando uma linha divisória entre a historiografia republicana e a imperial. O impacto do estabelecimento do Principado na História é descrito nos mesmos termos que o fora com relação à eloquência no discurso de Secundus. No passado, grandes eventos se ofereciam para tratamento pelo historiador, ao qual cabia conservar a memória (Annales, IV, 32, 2). No presente, pelo contrário, há apenas fatos menores a serem lembrados (Annales, IV, 34, 3). Assim como no Dialogus é dito que a eloquência declinara com a paz, o mesmo ocorreu com a história. Na introdução de Histórias, Tácito já mencionara este dado:

\begin{abstract}
Após a fundação da cidade, oitocentos e vinte anos antes de nossa época, muitos autores trataram, quando os feitos do povo romano eram lembrados em igual eloquência e liberdade. Depois que se lutou em Ácio e que todo poder a um foi conferido para a paz estar presente, aqueles grandes talentos se detiveram. (Historiae, I, 2).
\end{abstract}

Contudo, Tácito acrescenta que procurará superar esta limitação estabelecendo uma relação de causa e efeito entre pequenos e grandes fatos (Annales, IV, 32, 4). Na segunda parte (Annales, IV, 33) ele explica sua posição. Em primeiro lugar, afirma que o Principado deve ser aceito, pois não há como existir uma forma de governo que combine democracia, aristocracia e monarquia (Annales, IV, 33, 1). Esta imagem do Estado romano foi proposta por Políbio e retoma- 
da por Cícero no seu tratado De Re Publica (OLTRAMARE, 1932, p. 67-68). Ao rejeitar este ideal, Tácito também indica que os escritos dos historiadores da República pouca utilidade têm em um regime exclusivamente monárquico, no qual a plebe e o Senado detêm pouco poder (Annales, IV, 33, 2). Neste contexto em que o imperador representa o Estado, é nele que a narrativa histórica deve centrar-se. Tácito conforma seu método analítico a este fato (GINSBURG, 1984, p. 86).

Tendo em vista estas considerações, Tácito propõe como função da História antes a de indicar aos leitores como agir neste regime político do que propriamente de deleitá-los com uma narrativa de grandes eventos, já que estes não têm mais lugar. Por sua vez, esta função proposta por Tácito combinaria com o modo como seus leitores a interpretariam:

Poucos discernem por prudência as coisas honestas das más, as úteis das prejudiciais, a maioria é ensinada pelo que acontece aos outros. (Annales, IV, 33, 2).

Mesmo que as próprias famílias já estejam extintas, encontrarás os que pela semelhança dos costumes julgam os maus feitos alheios imputados a si. (Annales, IV, 33, 5).

Tácito valoriza, portanto, a história do Principado como fonte de exempla. ${ }^{11}$ Dentre as várias passagens em que este tema está presente (GINSBURG, 1993, p. 86, n. 3), há uma que sintetiza bem o pensamento do historiador a respeito:

Nem tudo entre os antepassados era melhor, mas também nossa época produziu muito de mérito e de talentos que deve ser imitado pelos pósteros. (Annales, III, 55, 8).

Uma das críticas de Tácito é a de que se valoriza o passado e não se indaga sobre os fatos mais recentes. Ao comentar a morte de Arminius, chefe germano que combateu contra Roma, lamenta que "enquanto exaltamos os fatos antigos, temos pouca curiosidade pelos recentes" (Annales, II, 88, 4). Ideia que também encontramos na introdução da Vida de Agricola e, como foi mencionado, no Dialogus, 
no segundo discurso de Aper (Dialogus, XV, 1; XVIII). Para Tácito, tomando-se como referência este princípio da superioridade do presente frente ao passado, a questão que se coloca é a de mostrar qual a melhor conduta para o Principado. O procedimento que usa para respondê-la consiste em apresentar os extremos que tal conduta pode assumir. Ele qualifica de libertas (liberdade) a conduta honesta, exemplificando-a com a figura de senadores que se opuseram ao imperador. Tácito reconhece que esta estratégia é a mais honrosa, que favorece a obtenção de fama e glória pelos que a praticam, mas que tem o inconveniente de geralmente acarretar a morte, e daí sua pouca utilidade para o bem público (WIRSZUBSKI, 1968, p. 166). A conduta oposta ele a chama de seruitus (escravidão), palavra com a qual caracteriza a adulação do imperador por parte de alguns senadores e cavaleiros. É um comportamento útil, pois favorece uma boa relação com o imperador, mas não é honroso e denigre a imagem do corpo senatorial. Diante disso, Tácito sugere, ainda que em poucas passagens, que o ideal seria a equidade, um meio-termo, embora reconheça a dificuldade de alcançá-lo (Annales, IV, 20, 7). O melhor exemplo de indivíduo que logrou atingir esta meta é o de seu sogro, Julius Agricola:

Quanto aos jogos e as vãs honras se conduziu por um meio entre a medida e a profusão, não só longe da suntuosidade como também mais perto do renome. (Agricola, VI)

Agricola temperou seu vigor e reprimiu o ardor para não se destacar, conhecedor do respeito e versado no juntar o útil com o honesto. (Agricola, VIII)

As virtudes que permitem esta realização da equidade são, para Tácito, a moderatio e a prudentia (Agricola, IX; XL, .4; XLII, 3). Como observou C. J. Classen (1988, p. 97), “embora Tácito se mostre ansioso em enfatizar que Agricola evitou todas as formas de excesso, realça que ele assumiu quaisquer atitudes apropriadas de acordo com o tempo, circunstâncias e indivíduos envolvidos". Como Tácito deixa claro no trecho dos Anais mais acima citado, os que não possuem prudentia devem ser instruídos mediante a leitura da Histó- 
ria. ${ }^{12}$ A qualidade de saber evitar os excessos e escolher o conveniente também deve ser buscada pelo próprio historiador. A célebre afirmação de Tácito de que narrará os principados de Tibério a Nero sine ira et studio (Annales, I, 1, 4), em vez de confissão de imparcialidade frente à documentação, é antes um posicionamento ético, indicando ao leitor que procurará o justo meio em sua narrativa, diferindo daqueles historiadores que apenas escreveram adulações (Annales, I, 1, 2). No exórdio das Histórias, Tácito relaciona sua postura ética no regime imperial, indiretamente justificando sua ascensão neste, com a forma pela qual narrará os fatos que tiveram lugar após a morte de Nero:

Galba, Oto e Vitélio nem por benefício nem por injúria são por mim conhecidos. Nossa dignidade foi iniciada por Vespasiano, por Tito elevada e, não nego, por Domiciano mais longe avançada. Mas por declarar uma fé incorrupta nem por amor e sem ódio, qualquer um é mencionado. (Historiae, I, 1, 5).

É estabelecida uma relação entre o falar e o agir do historiador, assim como ao longo do Dialogus se estabelece uma que diz respeito ao orador e ao poeta. A questão da equidade na obra de Tácito não se restringe apenas ao âmbito das condutas individuais, mas também está presente na descrição que faz dos processos legais nos Anais. Examinando o conceito de justiça em Tácito, Michèle Ducos conclui que o historiador não defende uma aplicação estrita das leis e nem propostas de leis generalizantes, mas uma que considere a equidade, ou seja, que tome cada caso em particular. E, neste sentido, Tá-cito se inscreveria numa tradição, com origem no mundo grego e que permanece no pensamento romano, principalmente através de Cícero, a qual adota a noção do aequum et bonum (DUCOS, 1990, p. 107). Como vimos no discurso de Messalla no Dialogus, Tácito refere-se à relação ciceroniana entre Retórica e Ética ao apresentar a tarefa do orador republicano. ${ }^{13}$

A equidade é também um elemento buscado pela ficção, a qual tem a função de examinar qualitativamente as condutas humanas (EDEN, 1982, p. 34). De fato, no Dialogus é atribuída à tragédia esta finalidade ética, que acaba por ser a mesma que a da História. Ambas 
devem, segundo Tácito, criticar os excessos e propor uma conduta adequada. Podemos observar isto no próprio modo como Tácito apresenta a recepção pela audiência da tragédia, no Dialogus, e da história, nos Anais. Tanto os leitores da narrativa histórica (WOODMAN e KRAUS, 1997, p. 93) como os que ouvem a recitação de uma tragédia estão atentos aos duplos significados implícitos. Quando, no primeiro discurso de Aper, Tácito comentou sobre a recepção da tragédia de Maternus, afirmou que a audiência interpretava esta como uma crítica indireta a si, colocando em risco o poeta. A relevância da figura de Maternus no Dialogus reside no fato de Tácito atribuir ao poeta trágico a mesma função do orador na República. Como historiador, Tácito assume igual postura no Principado.

Quanto ao aspecto formal, alguns autores também ressaltam o paralelo entre história e tragédia em Tácito, situando principalmente os Anais na tradição do teatro grego e romano. Para Pierre Grimal, isto se observa no fato de a narrativa nesta obra centrar-se na figura do monarca, dado predominante seja na tragédia grega como na romana (GRIMAL, 1990, p. 10-11). Maria Jesús Ramírez Díez, por sua vez, chama a atenção para este paralelo no tocante à caracterização das personagens femininas nos Anais. Tomando o exemplo de Lívia, a autora enumera traços comuns entre a representação desta por Tácito e a das mulheres nos trágicos gregos (DÍEZ, 1994). ${ }^{14} \mathrm{~A}$ própria descrição de determinados episódios pelo historiador segue uma estrutura dramática, como no caso da morte de Agripina, mãe de Nero (Annales, XIV, 1-13) (DEVILLERS, 1995) e da conspiração de Pisão contra Nero em 65 (Annales, XV, 48-74) (WOODMAN, 1993).

Depreende-se, portanto, que uma análise da concepção de História em Tácito é mais matizada do que fazem supor os estudos que se preocupam em cobrar uma positividade factual da obra deste historiador. A inserção de Tácito na tradição da Nova Academia, com sua ênfase na equidade, e a aproximação entre a história e a tragédia, principalmente quanto à finalidade ética, são dois dados importantes que o Diálogo dos oradores coloca para uma reflexão sobre o conjunto dos escritos históricos deste autor. 
Ética, retórica e poética no Diálogo dos Oradores e a concepção...

\section{Ethics, Rhetoric, Poetics in the Dialogus de Oratoribus, and the Tacitean conception of History}

Abstract: This article analyzes the Dialogus de Oratoribus, its structure and themes in their relationship with the conception of History that underlines Tacitus' works as a whole. It is highlighted that Tacitus partakes the philosophic tradition of the New Academy, and its respective emphasis on equity, as well as the close ties between history and tragedy on what concerns their ethical ends.

Keywords: Dialogus de Oratoribus. Tacitus. Rhetoric. History.

\section{Notas}

${ }^{1}$ Ver, por exemplo, WOODMAN, 1988; KEITEL, 1993; SINCLAIR, 1995; MARQUES, 2008.

${ }^{2}$ Foram utilizadas as edições da Les Belles Lettres. Quanto às traduções citadas ao longo do texto, tive como base, para os Anais, a de Leopoldo Pereira (s/d), e, para as obras menores de Tácito, as de Agostinho da Silva (1974). As traduções das passagens das Histórias são de minha autoria.

${ }^{3}$ Sobre este debate, cf. LUCE, 1993, p. 11; MARTIN, 1989, p. 60.

${ }^{4}$ Cf. LUCE, 1993, p. 13.

${ }^{5}$ Segundo Brink (1993), Tácito estaria neste discurso a criticar a doutrina neociceroniana de Quintiliano.

${ }^{6}$ Cf. HEILMANN, 1989, p. 390.

${ }^{7}$ Cf. Dialogus, XVI, 7.

${ }^{8}$ Cf. Dialogus, XX, 3; XXIII, 3.

${ }^{9}$ Ao nos voltarmos para as obras históricas de Tácito, Virgílio e Lucano são dois poetas cujos versos dos poemas épicos são utilizados pelo escritor. Sobre Virgílio, ver SYME, 1967, p. 143 e 357, e, principalmente, WOODMAN, 1988, p. 171-176. Sobre Lucano, ver SYME, 1967, p. 143 e GRIMAL, 1990, p. 319. Horácio é pouco mencionado, apenas uma vez segundo SYME, 1967, p. 357.

${ }^{10}$ Como observa Etienne Aubrion (1990, p. 206-7): “Tacite semble avoir beaucoup de sympathie pour Maternus et approuver son engagement. Cela est confirmé par le fait que les seuls auteurs dramatiques qu'il cite dans les Annales son avec Sénèque et Lucain, les poètes Scaurus et Pomponius qui furent inquietés par le pouvoir. (...) Quoi qu'il en soit, Tacite considère que cette poésie dramatique peut avoir la même fonction que l'histoire".

${ }^{11}$ Conforme. Historiae, III, 51: exempla recti.

${ }^{12} \mathrm{O}$ estudo de Patrick Sinclair (1995), sobre o uso de sententiae nos seis primeiros livros dos Anais, endossa esta constatação. Formando máximas de caráter geral a partir da descrição de episódios históricos, o historiador almeja estabelecer uma

Anos 90, Porto Alegre, v. 16, n. 30, p. 19-43, dez. 2009 


\section{Fábio Duarte Joly}

ponte entre passado e futuro para indicar a seus leitores uma ética de ação no Principado.

${ }^{13}$ Conforme Dialogus, XXXI, 1-2. O fato de Tácito ter mencionado, na introdução do Dialogus, que cada interlocutor apresentou causas prováveis (probabilis causas adferrent, Dialogus, I, 3) para o declínio da oratória, é uma referência à doutrina da Nova Academia, segundo a qual a verdade seria inatingível, apenas sendo possível um conhecimento provável sobre as coisas (CHIAPPETTA, 1997, p. 78).

${ }^{14}$ Sobre a utilização de recursos presentes na tragédia por Tácito na caracterização de indivíduos, ver também COUSIN, 1951.

\section{Referências}

AUBRION, E. L'historien Tacite face à l'évolution des jeux et des autres spetacles. In: BLÄNDDORF, J. (Ed.). Theather und Gesellschaft im Imperium Romanum. Mainz: Francke Verlag, 1990, p. 197-211.

BARTSCH, S. Actors in the audience: theatricality and doublespeak from Nero to Hadrian. Cambridge: Harvard University Press, 1994.

BRINK, C. O. History in the Dialogus de Oratoribus and Tacitus the Historian: a new approach to an old source. Hermes, v. 121, 3, p. 335-349, 1993.

CHIAPPETTA, A. “Não diferem o historiador e o poeta...” O texto histórico como instrumento e objeto de trabalho. Lingua e Literatura, n. 22, p. 15-34, 1996.

- Ad animos faciendos: comoção, fé e ficção nas Partitiones oratoriae e no De officiis de Cícero. Tese (Doutorado) - FFLCH, USP, São Paulo, 1997.

CLASSEN, C. J. Tacitus - Historian between Republic and Principate. Mnemosyne, v. 41, 1-2, p. 93-116, 1988.

COUSIN, J. Rhétorique et psychologie chez Tacite. Revue des Études Latines, v. 28, p. 229-247, 1951.

DEVILLERS, D. Tacite, les sources et les impératifs de la narration: le récit de la mort d'Agripine (Annales XIV, 1-13). Latomus, v. 54, 2, p. 324-345, 1995.

DÍEZ, Maria Jesús Ramírez. Presupuestos filosóficos y arquetipos literarios presentes en el personaje de Livia en los Annales de Tácito. Estudios Clásicos, v. 106, p. $65-85,1994$.

DUCOS, M. La justice dans l'oeuvre de Tacite. Revue des Études Latines, v. 68, p. 99-111, 1990. 
Ética, retórica e poética no Diálogo dos Oradores e a concepção...

EDEN, K. Poetry and equity: Aristotle's defense of fiction. Traditio, v. 38, p. 17-43, 1982.

GERBER, A. \& GREEF, A. Lexicon Taciteum. Hildesheim: Georg Olms Verlagbuchhandlung, 1962.

GINSBURG, J. Tradition and theme in the Annals of Tacitus. New Hampshire: Ayer, 1984. . In maiores certamina: past and present in the Annals. In: LUCE, T.J. \& WOODMAN, A. J. (Eds.). Tacitus and the Tacitean tradition. New Jersey: Princeton University Press, 1993, p. 86-103.

GRIMAL, P. Tacite. Paris: Fayard, 1990.

GRUBE, G. M. A. The Greek and Roman critics. London: Methuen \& Co, 1965.

HEILMANN, W. 'Goldene Zeit' und geschichtliche Zeit im Dialogus de oratoribus: zur Geschichtsauffassung des Tacitus. Gymnasium, v. 96, n. 5, p. 385-405, 1989.

KEITEL, E. Speech and narrative in Histories 4. In: LUCE, T. J. e WOODMAN, A. J. (Eds.). Tacitus and the Tacitean tradition. New Jersey: Princeton University Press, 1993, p. 39-58.

LUCE, T. J. Reading and response in the Dialogus. In: LUCE, T. J. e WOODMAN, A. J. (Eds.). Tacitus and the Tacitean tradition. New Jersey: Princeton University Press, 1993, p. 11-38.

MARQUES, J. B. Uma análise dos estudos críticos sobre Tácito. Aletheia, v. 1, n. 1, p. 1-11, 2008.

MARTIN, R. Tacitus. London: Bristol Classical Press, 1989.

OLTRAMARE, A. La réaction cicéronienne et les débuts du Principat. Revue des Études Latines, v. 10, p. 58-90, 1932.

SINCLAIR, P. Tacitus the sententious historian: a sociology of rhetoric in Annales 1-6. Pennsylvania: Pennsylvania State University Press, 1995.

SYME, R. Tacitus. Oxford: Oxford University Press, 1967. 2 v.

TACITE. Annales. Texte établi et traduit par Henri Goelzer. Paris: Les Belles Lettres, $1953.3 \mathrm{v}$.

. Vie d'Agricola. Texte établi et traduit par E. de Saint-Denis. Paris: Les Belles Lettres, 1948. $1951.2 \mathrm{v}$.

Histoires. Texte établi et traduit par Henri Goelzer. Paris: Les Belles Lettres, Dialogue des orateurs. Texte établi par Henri Goelzer et traduit par Henri Bornecque. Paris: Les Belles Lettres, 1936.

Anos 90, Porto Alegre, v. 16, n. 30, p. 19-43, dez. 2009 


\section{Fábio Duarte Joly}

TÁCITO. Anais. Tradução Leopoldo Pereira. São Paulo: Ediouro, s/d. . Obras menores. Tradução Agostinho da Silva. Lisboa: Horizonte, 1974.

VON ALBRECHT, M. Storia della letteratura latina. Torino: Einaudi, 1995. 2 v.

WIRSZUBSKI, Ch. Libertas as a political idea at Rome during the late Republic and Early Principate. Cambridge: Cambridge University Press, 1968.

WOODMAN, A. J. Rhetoric in classical historiography. Portland: Areopagitica Press, 1988. Amateur dramatics at the court of Nero: Annals 15. 48-74. In: LUCE, T. J. e WOODMAN, A. J. (Eds.). Tacitus and the Tacitean tradition. New Jersey: Princeton University Press, 1993, p. 104-128.

WOODMAN, A. J. e KRAUS, C. S. Latin Historians. In: Greece \& Rome New Surveys in the Classics $N^{\circ} 27$. Oxford: Oxford University Press, 1997. 